\title{
MENINGKATKAN KEMAMPUAN PEMECAHAN MASALAH MATEMATIK DAN SELF EFFICACY SISWA SMP MENGGUNAKAN PENDEKATAN CONTEXTUAL TEACHING AND LEARNING
}

\author{
Devi Gustia $^{1}$, Jenab Hanifah ${ }^{2}$, Muhammad Afrilianto ${ }^{3}$ \\ 1,2,3 IKIP Siliwangi, Jln Terusan Jendral Sudirman, Cimahi, Jawa Barat, Indonesia \\ 1deeviigustia248@gmail.com,2 jenabhanifah75@gmail.com,3 \\ muhammadafrilianto1@ikipsiliwangi.ac.id
}

\begin{abstract}
This study aimed to determine the improvement of mathematical problem solving abilities and self efficacy students of Junior High School through the Contextual Teaching and Learning approach. The method of this research is the quasi-experimental method with the research design of the post-test control group design. The population in this study was the seventh grade of SMPN 1 TelukJambe Barat City of Karawang. Determination of the sample is done by the technique used which is not random so the class selected as the experimental class is class VII $\mathrm{D}$ and VII A as the control class. Instruments given to students in the form of test questions (pretest-posttest) related to indicators of mathematical problem solving abilities. Analysis of data processing was carried out on the results tests of mathematical problem solving abilities of students at SMPN 1 TelukJambe Barat. The analysis of the study used the average difference test. The results of the study concluded: (1) Achievement and improvement of mathematical problem solving skills that are learned by using contextual teaching and learning approaches are better than students who receive learning with a scientific approach. (2) Mathematical self efficacy of students who learn to use Contextual Teaching and Learning is better than students with learning using a scientific approach.
\end{abstract}

Keywords: Mathematical Problem Solving, Self Efficacy, Contextual Teaching and Learning Approach

\begin{abstract}
Abstrak
Penelitian ini bertujuan untuk mengetahui peningkatan kemampuan pemecahan masalah matematik dan self efficacy siswa SMP melalui pendekatan Contextual Teaching and Learning. Metode penelitian ini adalah metode kuasi eksperimen dengan desain penelitian pretest-posttest control group design. Populasi dalam penelitian ini adalah kelas VII SMP Negeri 1 TelukJambe Barat kota Karawang. Penentuan sampel dilakukan dengan teknik yang digunakan yaitu tidak acak (random) sehingga kelas yang terpilih sebagai kelas eksperimen adalah kelas VII D dan VII A sebagai kelas kontrol. Instrumen yang diberikan kepada siswa berupa soal tes (pretestposttest) yang berkaitan dengan indikator kemampuan pemecahan masalah matematik. Analisis pengolahan data dilakukan terhadap hasil tes kemampuan pemecahan masalah matematik siswa di SMPN 1 TelukJambe Barat. Analisis penelitian menggunakan uji perbedaan rata-rata. Hasil penelitian didapat kesimpulan: (1) Pencapaian dan peningkatan kemampuan pemecahan masalah matematik yang mendapat pembelajaran dengan pendekatan Contextual Teaching and Learning lebih baik daripada siswa yang mendapat pembelajaran dengan pendekatan saintific (2) Self efficacy matematik siswa yang pembelajarannya menggunakan Contextual Teaching and Learning lebih baik daripada siswa dengan pembelajaran yang menggunakan pendekatan saintific.
\end{abstract}

Kata Kunci: Kemampuan Pemecahan Masalah, Self Efficacy, Pendekatan Contextual Teaching and Learning 
How to cite: Gustia, D., Hanifah, J., \& Afrilianto, M., (2019). Meningkatkan Kemampuan Pemecahan Masalah Matematik Dan Self Efficacy Siswa SMP Menggunakan Pendekatan Contextual Teaching and Learning. JPMI - Jurnal Pembelajaran Matematika Inovatif, 2 (5), 253 260.

\section{PENDAHULUAN}

Pendidikan menjadi hal yang sangat penting bagi kemajuan suatu bangsa. Untuk itu perlu adanya perbaikan secara terus menerus akan mutu pendidikan itu sendiri. Dalam peningkatan mutu pendidikan yang di dalam ada perbaikan individu, matematika memiliki peranan penting karena erat kaitannya dalam kehidupan sehari-hari. Matematika sangat berperan penting dalam kehidupan karena dewasa ini perkembangan teknologi modern mendorong masyarakat untuk cepat mengolah informasi. Sesuai dengan yang disebutkan National Council of Teacher of Mathematics (Sumarmo, 2013) prinsip pengajaran menyebutkan bahwasanya dalam mengajar matematika yang efisien mengupayakan siswa agar tahu dan sadar akan pentingnya belajar matematika, kemudian mereka harus didukung untuk belajar matematika sebaik mungkin. sedangkan prinsip belajar menyebutkan bahwa siswa harus menguasai matematika dengan pemahaman dan membangun pengetahuan.

Susunan matematika terdiri dari tingkatan yang paling mudah dipahami sampai yang paling sulit dan rumit untuk dipahami. Oleh karenanya matematika juga merupakan kegiatan pemahaman yang tinggi yang berkaitan dengan struktur-struktur, hubungan-hubungan, simbolsimbol, keabstrakan, dan dapat diterapkan di kehidupan sehari-hari (Suherman, 2003). Jadi, belajar matematika merupakan kegiatan yang berhubungan erat dengan lingkungan sekitar baik secara langsung ataupun tidak langsung.

Pemecahan masalah sebagai jantungnya matematika merupakan kemampuan dasar dalam belajar matematika. Zanthy (2016) mengungkapkan bahwa keberhasilan seserang dalam kehidupannya salah satunya ditentukan oleh keterampilan berpikirnya, utamanya dalam memecahka masalah dalam kehidupan sehari-hari yang dihadapinya. Oleh karenanya kemampuan pemecahan masalah itu sendiri harus ditingkatkan dengan cara memberikan pembelajaran yang bermakna (Hidayat \& Sariningsih, 2018). Solusi dari soal pemecahan masalah memiliki empat tahap penyelesaian menurut Polya, yaitu: memahami masalah, merencanakan pemecahannya, menyelesaikan masalah sesuai rencana langkah kedua, memeriksa kembali hasil yang telah dikerjakan (Hendriana \& Soemarmo, 2017). Siswa dapat menguasai kemampuan pemecahan masalah matematik dengan baik jika siswa itu sendiri menguasai kemampuan afektif, salah satunya adalah self efficacy.

Kenyataan di lapangan menunjukkan bahwa siswa dalam belajar matematika hanya mencontoh penyelesaian soal yang dikerjakan gurunya. Jika siswa diberikan soal yang sifatnya non rutin atau soal-soal yang dituntut untuk berpikir tingkat tinggi, maka mereka akan kebingungan karena ketidakpahaman dalam melakukan penyelesaian. Berdasarkan hasil wawancara yang dilakukan guru menyatakan bahwa apabila siswa diberikan soal yang berbeda dari contoh yang diberikan atau soal yang dalam penyelesaiannya membutuhkan strategi, maka hanya beberapa siswa yang mampu menyelesaikannya sedangkan sebagian besar siswa merasa kesulitan.

Self-efficacy (kemampuan diri) merupakan suatu sikap yakin yang harus dimiliki siswa agar mampu mengikuti proses pembelajaran dengan baik. Seperti yang diungkapkan oleh Popham (Hairida \& Erlina, n.d.) bahwa kemampuan afektif berperan penting atas keberhasilan 
seseorang. Ada beberapa hal yang dapat mempengaruhi hasil belajar siswa yaitu minat, sikap, konsep diri, nilai dan moral. Menurut Bandura (Mareta, 2014), self efficacy adalah kepercayaan atau keyakinan seseorang bahwa ia dapat menguasai situasi dan menghasilkan sesuatu yang positif.

Menurut Hendriana (2012) menyatakan bahwa kepercayaan diri dapat memperkuat motivasi mencapai keberhasilan, karena apabila kepercayaan diri terhadap kemampuan diri semakin tinggi, maka semakin kokoh untuk mengerjakan permasalahan yang ada. Tekad yang kuat untuk meraih keberhasilan dalam menyelesaikan suatu tugas yang sudah di targetkan harus tertanam dan menjadi motivasi bagi siswa. siswa harus berkomitmen untuk mencapai hasil akhir dengan kerja tuntas. Oleh karena itu, kemampauan self efficacy harus ditanamkan dalam diri siswa agar terwujudnya proses pembelajaran matematika penuh makna untuk diterapkan dalam kehidupan nyata.

Salah satu pendekatan pembelajaran yang berpotensi untuk meningkatkan kemampuan pemecahan masalah dan self efficacy matematik siswa adalah pembelajaran dengan contextual teaching and learning yang mana siswa itu sendiri diajak untuk dapat memahami suatu masalah berkaitan dengan kehidupan sehari-hari (Muslich, 2007). Berikut adalah indikator dalam pendekatan contextual teaching and learning, 1) konstruktivisme, 2) bertanya, 3) menemukan, 3) masyarakat belajar, 4) pemodelan, 5) refleksi, dan 6) penilaian otentik (Rusman \& Pd, 2012). Dengan itu, dapat ditarik kesimpulan bahwa rumusan masalah dalam makalah ini yaitu sebagai berikut:(1) Apakah dengan menggunakan pendekatan Contextual Teaching And Learning dapat meningkatkan kemapuan pemecahan masalah matematik siswa dibandingkan dengan pembelajaran saintific? (2) Apakah dengan menggunakan pendekatan Contextual Teaching And Learning dapat meningkatkan kemampuan diri (self efficacy) siswa dibandingkan dengan pembelajaran saintific?

Yang menjadi tujuan dari penelitian ini yaitu :1) Untuk mengetahui apakah terdapat peningkatan kemampuan pemecahan masalah matematik antara pembelajaran menggunakan Pendekatan Contextual Teaching and Learning dengan pembelajaran menggunakan Pendekatan Konvensional, 2) Untuk mengetahui apakah terdapat peningkatan kemampuan diri (self efficacy) antara pembelajaran menggunakan pendekatan Contextual Teaching and Learning dengan pembelajaran yang menggunakan pendekatan Konvensional.

\section{METODE}

Metode penelitian ini adalah metode kuasi eksperimen yang pemilihan subjeknya tidak acak dengan desain penelitian pretest-postest control group design (Hendriana \& Afrilianto, 2017). Dalam penelitian ini terdapat dua kelas yang mendapatkan perlakuan yang berbeda. Dimana kelas eksperimen memperoleh pembelajaran dengan pendekatan Contextual Teaching And Learning dan kelas kontrol memperoleh pembelajaran dengan pendekatan saintific. Selanjutnya pada kedua kelas itu dilakukan tes hasil belajar yang sama. Hasil tes kedua kelompok di uji secara statistik untuk melihat apakah ada perbedaan yang terjadi karena adanya perlakuan yaitu pembelajaran dengan pendekatan Contextual Teaching and Learning. Dengan desain penelitian sebagai berikut:
A $\quad \mathrm{O} \quad \mathrm{X}$
$\mathrm{O}$
$\mathrm{A} \quad \mathrm{O} \quad \mathrm{O}$

Keterangan: $\quad \mathrm{A}=$ Pengelompokkan subjek secara acak kelas 


$$
\begin{aligned}
& \mathrm{O}=\text { Pretes Postes } \\
& \mathrm{X}=\text { Pembelajaran menggunakan CTL }
\end{aligned}
$$

Instrumen yang di gunakan dalam penelitian adalah tes kemampuan pemecahan masalah matematis dan skala self efficacy. Tes kemampuannya sendiri berbentuk essay (Pretes dan Postes), yang berjumlah 5 soal dan skala self efficacy disusun atas dasar indikator-indikator yang merupakan ciri-ciri dari sikap yang akan diteliti dan pertanyaan-pertanyaan tersebut harus diisi oleh siswa. Teknik dari pengambilan data self efficacy dilakukan dengan menyebar angket. Model Likert adalah skala yang digunakan dalam penelitian dengan terdapat empat alternatif jawaban yang terdiri dari SS (Sangat Setuju), S (Setuju), TS (Tidak Setuju), STS (Sangat Tidak Setuju).

\section{HASIL DAN PEMBAHASAN}

\section{Hasil}

Data terkait self efficacy diperoleh dari angket yang diberikan pada akhir perlakuan pada kedua kelas yaitu kelas eksperimen dan kelas kontrol. Skala data self efficacy dari kedua kelas tergolong ordinal, untuk melihat perbedaan self efficacy kelas eksperimen dan kelas kontrol dilakukan uji statistika Independent-Sampel T-Tes yaitu uji perbedaan rata-rata. Dari data siswa kedua kelompok diperoleh skor minimun ( $x$ min) dan skor maksimun ( $x$ max), skor, rerata, standar deviasi, seperti pada Tabel 1.

Tabel 1. Hasil Skala Self Efficacy Siswa

\begin{tabular}{lccccc}
\hline \multirow{2}{*}{ Kelompok } & \multirow{2}{*}{ Skor Ideal } & \multicolumn{4}{c}{ Self Efficacy } \\
\cline { 3 - 6 } Eksperimen & 40 & 3 & 4 & 75,7 & 3,72 \\
\cline { 2 - 6 } Kontrol & 40 & 1 & 4 & 68,5 & 3,75 \\
\hline
\end{tabular}

Dari hasil di atas menunjukan bahwa self efficacy kelas eksperimen lebih baik daripada self efficacy kelas kontrol, artinya siswa di kelas eksperimen mempunyai kemampuan diri untuk menyelesaikan tugas kemampuan pemecahan masalah matematik yang diberikan dengan baik. Hal ini dapat dilihat dari hasil persentase rerata skor self efficacy kelas eksperimen lebih besar 7,2 dari kelas kontrol.

Berdasarkan aspek pemecahan masalah matematik yang di ukur melalui hasil skor pretest dan posttest, di dapatkan skor rata-rata dan simpangan baku (s). Data ditunjukan pada Tabel 2 sebagai berikut :

Tabel 2. Statistika Deskriptif Kemampuan Tes Kemampuan Pemecahan Masalah Matematik

\begin{tabular}{lccccc}
\hline \multirow{2}{*}{ Kelompok } & Skor & \multicolumn{2}{c}{ Pretest } & \multicolumn{2}{c}{ Postest } \\
\cline { 3 - 6 } Eksperimen & Ideal & $\overline{\mathbf{x}}$ & $\mathbf{S}$ & $\overline{\mathbf{x}}$ & $\mathbf{S}$ \\
Kontrol & 100 & 52,17 & 8,375 & 79,50 & 4,974 \\
& 100 & 51,83 & 7,598 & 64,33 & 6,937 \\
\hline
\end{tabular}


Tabel.2 di atas memperlihatkan bahwa rata-rata skor yang diperoleh pada pretes kelas eksperimen dan kelas kontrol tidak jauh berbeda dengan simpangan bakunya kelas kontrol adalah 7,59 sedangkan simpangan baku kelas eksperimen 8,37. Dalam hal ini menunjukan bahwa kedua kelompok sampel tidak jauh berbeda dengan kualifikasi masing-masing kelompok sampel berada pada katagori kurang. Sedangkan hasil dari postes menunjukan bahwa kelas eksperimen lebih unggul dibandingkan dengan kelas kontrol. Rata-rata kelas eksperimen sebesar 15,17 lebih besar daripada kelas kontrol.

Hipotesis yang diuji pada masing-masing data gain ternormalisasi kemampuan pemecahan masalah matematis mahasiswa pada kelas eksperimen maupun kelas kontrol adalah:

Ho : sampel berasal dari populasi data berdistribusi normal

Ha : sampel berasal dari populasi data berdistribusi tidak normal

Kriteria pengujian, jika $\mathrm{P}$ value (sig.) $>$, maka Ho diterima dan jika $\mathrm{P}$ value (sig.) $<$, maka Ho ditolak, dengan taraf signifikan sebesar $=0,05$. Hasil uji normalitas skor gain ternormalisasi dapat dilihat pada tabel berikut ini:

Tabel 3. Uji Normalitas

\begin{tabular}{llll}
\hline Kelas & \multicolumn{2}{l}{ Kemampuan Pemecahan Masalah } & \\
\hline & Shapiro-Wilk & & \\
& Statistic & Df & Sig. \\
Eksperimen & 0,804 & 30 & 0,000 \\
Kontrol & 0,948 & 30 & 0,145 \\
\hline
\end{tabular}

Uji normalitas kemampuan pemecahan masalah matematik siswa yang pembelajarannya menggunakan CTL dengan Uji Shapiro-Wilk diperoleh nilai Sig. kurang dari nilai 0,05. Tetapi, untuk kemampuan pemecahan masalah matematis yang pembelajaraanya menggunakan pendekatan saintific nilai Sig. lebih dari nilai 0,05. Ini berarti untuk uji homogenitas tidak dapat dilakukan karena ada salah satu kelompok yang berasal dari populasi data berdistribusi tidak normal. Selanjutnya dilakukan Uji MannWhitney untuk kemampuan pemecahan masalah matematik siswa.

Untuk mengetahui apakah ada perbedaan rata-rata gain kemampuan pemecahan masalah kedua kelompok maka dilakukan Mann Whitney. Hipotesis statistika yang di uji adalah:

Ho : Peningkatan kemampuan pemecahana masalah matematik siswa yang pembelajarannya menggunakan CTL tidak lebih baik daripada pembelajaran yang menggunakan pendekatan saintific.

H1: Peningkatan kemampuan pemecahan masalah matematis siswa yang pembelajarannya menggunakan CTL lebih baik daripada pembelajaran yang menggunakan pendekatan saintific.

Ho : $\mu 1 \leq \mu 2$ (peningkatan kemampuan pemecahan masalah matematis siswa yang pembelajarannya menggunakan pendekatan CTL tidak lebih baik daripada yang menggunakan pembelajaran saintific) 
H1 : $\mu 1>\mu 2$ (peningkatan kemampuan pemecahan masalah matematis siswa yang pembelajarannya menggunakan pendekatan CTL lebih baik daripada yang menggunakan pembelajaran saintific)

Tabel 4. Uji Mann-Whitney Gain Ternormalisasi Kemampuan Pemecahan Masalah Matematik

\begin{tabular}{llllccc}
\hline Kelas & \multicolumn{7}{l}{ Kemampuan Pemecahan Masalah } & \\
\cline { 2 - 7 } & $\mathrm{N}$ & Mean Rank & Sum Ranks & of & Mann Whitney & $\begin{array}{l}\text { Asymp. } \\
\text { Sig. }(2- \\
\text { tailed) }\end{array}$ \\
Eksperimen & 30 & 45,50 & 1365,00 & & 0,000 & 0,000 \\
Kontrol & 30 & 15,50 & 465,00 & & \\
\hline
\end{tabular}

Berdasarkan Tabel 4. Nilai sig.(1-pihak) adalah 0,000 yang didapatka kurang dari 0,05, sehingga Ho ditolak. Artinya kelas yang menggunakan pendekatan CTL lebih baik dibandingkan dengan siswa yang menggunakan pembelajaran saintific.

\section{Pembahasan}

Berdasarkan hasil analisis data self efficacy siswa untuk kelas eksperimen dan kelas kontrol. Didapatkan nilai rata-rata self efficacy siswa kelas eksperimen yang pembelajarannya menggunakan pendekatan CTL lebih baik daripada kelas kontrol yang menggunakan pembelajaran saintific.

Pada saat kegiatan pembelajaran di kelas, peneliti menemukan bahwa kelas yang diberikan penanganan lebih aktif dan percaya diri pada saat kegiatan pembelajaran terutama pada saat kegiatan kelompok dalam menyelesaikan permasalahan-permasalahan yang diberikan dibandingkan kelas kontrol yang cenderung lebih pasif. Bahkan sejauh pengamatan yang dilakukan selama pembelajaran berlangsung, pada kelas eksperimen siswa banyak menunjukan perilaku positif sesuai dengan indikator self efficacy siswa seperti yakin akan keberhasila diri, mampu mengatasi masalah yang dihadapi, berani mengambil resiko, menyadari kekuatan dan kelemahan diri, tidak mudah menyerah juga mampu berinteraksi dengan orang lain.

Selanjutnya setelah diberikan perlakuan yang berbeda antara kelas eksperimen dan kelas kontrol, dari data tabel 2 menunjukan pencapaian serta peningkatan kemampuan pemecahan masalah matematik siswa kelas eksperimen yang pembelajarannya menggunakan pendekatan CTL lebih baik secara signifikan daripada kelas kontrol yang menggunakan pembelajaran saintific. Itu juga ditunjukan dengan interaksi yang berlangsung pada proses pembelajaran di kelas eksperimen pun mengalami peningkatan yang cukup baik dibandingkan kelas kontrol, dengan berani mengungkapkan gagasan yang mereka miliki.

Hal itu disebabkan siswa sudah paham dengan pembelajaran CTL dan sangat antusias menunggu pengarahan dari guru apa harus di ukur/dihitung, siswa sangat fokus dan semangat saat diberikan suatu permasalahan yang nyata, hal tersebut menjadikan siswa memiliki keyakinan dan kepercayaan diri untuk bisa menyelesaikan permasalahan yang dihadapinya. Hal tersebut sejalan dengan Ramachandran (2012) yang mengatakan bahwa kontribusi yang aktif dalam sebuah tugas dapat didrg dari keyakinan diri yang tinggi yang kemudian akan meningkatkan kemampuian berfikir seseorang. Secara keseluruhan kemampuan pemecahan masalah matematik guru meningkat secara signifikan. Hal ini karena penerapan model 
pembelajaran $C T L$ melibatkan siswa secara aktif dalam proses pembelajaranPembahasan harus menjadi interpretasi hasil bukan pengulangan dari analisis data.

\section{KESIMPULAN}

Dari hasil penelitian juga pembahasan yang telah dijelaskan disimpulkan bahwa pendekatan Contextual Teaching and Learning (CTL) dapat meningkatkan kemampuan pemecahan masalah matematik siswa di bandingkan dengan pembelajaran saintific, serta pendekatan Contextual Teaching and Learning (CTL) dapat menumbuhkan self efficacy siswa di bandingkan dengan pembelajaran saintific.

\section{DAFTAR PUSTAKA}

Hairida, H., \& Erlina, E. (n.d.). Korelasi antara Self-efficacy dengan Hasil Belajar Siswa dalam Mata Pelajaran Kimia di SMA. Jurnal Pendidikan Dan Pembelajaran Untan, 2(9).

Hendriana, H. (2012). Pembelajaran matematika humanis dengan metaphorical thinking untuk meningkatkan kepercayaan diri siswa. Infinity Journal, 1(1), 90-103.

Hendriana, H., \& Afrilianto, M. (2017). Langkah Praktis Penelitian Tindakan Kelas Bagi Guru. Bandung: Refika Aditama.

Hendriana, H., \& Soemarmo, U. (2017). Penilaian Pembelajaran Matematika Edisi Revisi. Bandung: PT Refika Aditama.

Hidayat, W., \& Sariningsih, R. (2018). Kemampuan Pemecahan Masalah Matematis dan Adversity Quotient Siswa SMP Melalui Pembelajaran Open Ended. JNPM (Jurnal Nasional Pendidikan Matematika), 2(1), 109-118.

Mareta Dwi Rakhmada, Y. (2014). Pendekatan Hands On Activity Melalui Modified Inquiry Untuk Meningkatkan Self Efficacy Siswa Kelas Xisman 1 Tuban Pada Materi Pokok Laju Reaksi (Hands On Activity Approach Through Modified Inquiryto Improve Self Efficacy In Xi Grade Of Sman 1 Tubansubject Matter Of The Rate Of Reaction). Unesa Journal Of Chemical Education, 3(1).

Muslich, M. (2007). KTSP: pembelajaran berbasis kompetensi dan kontekstual, panduan bagi guru, kepala sekolah, dan pengawas sekolah. Bumi Aksara.

Ramachandran, V. S. (2012). Encyclopedia of human behavior. Academic Press.

Rusman, D., \& Pd, M. (2012). Model-model pembelajaran. Raja Grafindo, Jakarta.

Suherman, E. (2003). Evaluasi pembelajaran matematika. Bandung: Upi.

Sumarmo, U. (2013). Berpikir dan Disposisi matematik serta Pembelajarannya. Universitas Pendidikan Indonesia. Bandung.

Zanthy, L. S. (2016). Pengaruh Motivasi Belajar Ditinjau dari Latar Belakang Pilihan Jurusan Terhadap Kemampuan Berpikir Kritis Mahasiswa di STKIP Siliwangi Bandung. Teorema: Teori Dan Riset Matematika, 1(1), 47-54. 
